\title{
Etiology of atopy in infancy: the KOALA Birth Cohort Study.
}

Citation for published version (APA):

Kummeling, I., Thijs, C., Penders, J., Snijders, B. E. P., Stelma, F. F., Reimerink, J., Koopmans, M., Dagnelie, P. C., Huber, M., Jansen, M. C. J. F., de Bie, R. A., \& van den Brandt, P. A. (2005). Etiology of atopy in infancy: the KOALA Birth Cohort Study. Pediatric Allergy and Immunology, 16(8), 679-684. https://doi.org/10.1111/j.1399-3038.2005.00333.x

Document status and date:

Published: 01/01/2005

DOI:

10.1111/j.1399-3038.2005.00333.x

Document Version:

Publisher's PDF, also known as Version of record

\section{Please check the document version of this publication:}

- A submitted manuscript is the version of the article upon submission and before peer-review. There can be important differences between the submitted version and the official published version of record.

People interested in the research are advised to contact the author for the final version of the publication, or visit the DOI to the publisher's website.

- The final author version and the galley proof are versions of the publication after peer review.

- The final published version features the final layout of the paper including the volume, issue and page numbers.

Link to publication

\footnotetext{
General rights rights.

- You may freely distribute the URL identifying the publication in the public portal. please follow below link for the End User Agreement:

www.umlib.nl/taverne-license

Take down policy

If you believe that this document breaches copyright please contact us at:

repository@maastrichtuniversity.nl

providing details and we will investigate your claim.
}

Copyright and moral rights for the publications made accessible in the public portal are retained by the authors and/or other copyright owners and it is a condition of accessing publications that users recognise and abide by the legal requirements associated with these

- Users may download and print one copy of any publication from the public portal for the purpose of private study or research.

- You may not further distribute the material or use it for any profit-making activity or commercial gain

If the publication is distributed under the terms of Article $25 \mathrm{fa}$ of the Dutch Copyright Act, indicated by the "Taverne" license above, 


\section{Etiology of atopy in infancy: The KOALA Birth Cohort Study}

Kummeling I, Thijs C, Penders J, Snijders BEP, Stelma F, Reimerink J, Koopmans M, Dagnelie PC, Huber M, Jansen MCJF, de Bie R, van den Brandt PA. Etiology of atopy in infancy: The KOALA Birth Cohort Study.

Pediatr Allergy Immunol 2005: 16:679-684. @ 2005 Blackwell Munksgaard

The aim of the KOALA Birth Cohort Study in the Netherlands is to identify factors that influence the clinical expression of atopic disease with a main focus on lifestyle (e.g., anthroposophy, vaccinations, antibiotics, dietary habits, breastfeeding and breast milk composition, intestinal microflora composition, infections during the first year of life, and gene-environment interaction). The recruitment of pregnant women started in October 2000. First, participants with 'conventional lifestyles' $(\mathrm{n}=2343)$ were retrieved from an ongoing prospective cohort study $(\mathrm{n}=7020)$ on pregnancy-related pelvic girdle pain. In addition, pregnant women $(n=491)$ with 'alternative lifestyles' with regard to child rearing practices, dietary habits (organic, vegetarian), vaccination schemes and/or use of antibiotics, were recruited through organic food shops, anthroposophic doctors and midwives, Steiner schools, and dedicated magazines. All participants were enrolled between 14 and $18 \mathrm{wk}$ of gestation and completed an intake questionnaire on family history of atopy and infant care intentions. Documentation of other relevant variables started in the pregnant mother and covered the first and third trimester as well as early childhood by repeated questionnaires at $14-18,30$, and $34 \mathrm{wk}$ of gestation and $3,7,12$, and 24 months postpartum. A subgroup of participants, including both conventional and alternative lifestyles, was asked to consent to maternal blood sampling, breast milk and a faecal sample of the infant at 1 month post-partum, capillary blood at age $1 \mathrm{yr}$, venous blood and observation of manifestation of atopic dermatitis during home visits at the age of $2 \mathrm{yr}$ (using the UK working party criteria and the severity scoring of atopic dermatitis index), and buccal swabs for DNA isolation from child-parent trios. From the start, ethical approval and informed consent procedures included gene-environment interaction studies. Follow-up at 3 and 7 months post-partum was completed with high response rates (respectively $90 \%$ and $88 \%$ in the conventional group, and $97 \%$ and $97 \%$ in the alternative group). The home visits at $2 \mathrm{yr}$ of age will be completed in 2005. Preliminary results show that we have succeeded in recruiting a large population with various lifestyle choices with a fairly large contrast with regard to dietary habits (including organic foods, vegetarian diet), vaccination schemes and/or use of antibiotics. We have also been able to collect a large number of faecal samples $(n=1176)$ and capillary blood samples at age $1 \mathrm{yr}(\mathrm{n}=956)$. Furthermore, a large proportion of the participants have consented with genetic studies. Mid 2006 we expect to report our first results on the relationship between the various exposures in early life and childhood atopy. An outline of the focus and design of the KOALA Birth Cohort Study is presented.

\author{
Ischa Kummeling', Carel Thijs ${ }^{1,2}$, John \\ Penders ${ }^{2}$, Bianca E. P. Snijders ${ }^{1}$, \\ Foekje Stelma ${ }^{3}$, Johan Reimerink', \\ Marion Koopmans ${ }^{4}$, Pieter C. \\ Dagnelie $^{2}$, Machteld Huber ${ }^{5}$, Margje \\ C. J. F. Jansen ${ }^{6}$, Rob de Bie ${ }^{i}$ and Piet \\ A. van den Brandt ${ }^{1}$ \\ ${ }^{1}$ Department of Epidemiology, Care and Public Health \\ Research Institute (Caphri), Maastricht University, \\ Maastricht, ${ }^{2}$ Department of Epidemiology, Nutrition \\ and Toxicology Research Institute Maastricht \\ (NUTRIM), Maastricht University, Maastricht, \\ ${ }^{3}$ Department of Medical Microbiology, University \\ Hospital of Maastricht, Maastricht, ${ }^{4}$ Diagnostic \\ Laboratory for Infectious Diseases, National Institute \\ for Public Health and the Environment, Bilthoven, \\ ${ }^{5}$ Louis Bolk Institute, Driebergen, ${ }^{6}$ TNO Nutrition and \\ Food Research, Zeist, The Netherlands
}

Key words: allergy; etiology; infant; risk factors; lifestyle; breast feeding; human milk; infections; gene-environment; diet; intestinal microbiota; cohort studies

Ischa Kummeling, Department of Epidemiology, Care and Public Health Research Institute (Caphri), Maastricht University, P.0. Box 616, 6200 MD, Maastricht, The Netherlands

Tel.: +31 433882385

Fax: +31 433884128

E-mail: ischa.kummeling@epid.unimaas.nl

Accepted 29 June 2005 
The prevalence of atopic diseases such as asthma, atopic eczema, and allergic rhinitis has increased over the past decades and currently $30 \%$ of the children in western societies show atopic symptoms (1). Atopic disease is thus an important public health problem, and preventive measures would be beneficiary. Despite years of research, little is yet understood concerning the etiologic pathways leading to these diseases. Atopic disorders typically run in families and therefore, genetic factors are supposed to be important (2). However, it is not likely that the frequency of polymorphisms in genes associated with the development of atopic diseases like asthma and eczema would have changed within the same two generations experiencing the increasing prevalence of atopy. Because of a change in environmental exposures, the population fraction exposed to important environmental influences may have changed, leading to an increased incidence of the expression of the atopic phenotype in previously unaffected but genetically susceptible individuals (2). An already existing genetic susceptible proportion of the population may have either become increasingly exposed to certain environmental risk factors which have become increasingly prevalent (3) or have become less exposed to various protective factors (4). Initially, in epidemiologic studies concerning atopy risk factors deserved most attention (e.g., dust mites, and ambient air pollution). More recently, however, the influence of various potentially protective factors (early microbial exposure, infections, pets, various immunologic and dietary factors in breast milk) has been emphasized. The role of a protective lifestyle was highlighted by a study reporting that growing up in anthroposophic families was protective against developing atopic disease (5). An anthroposophic lifestyle differs in many respects from living a conventional lifestyle, such as different dietary habits (e.g., a higher intake of fermented vegetables, consumption of mainly organic or biodynamically produced food, and a vegetarian diet), and restricted use of antibiotics and vaccinations. This lifestyle pattern reflects in part the traditional lifestyle of western societies several decades ago when the prevalence of atopy was lower than today but main characteristics may differ between countries.

This paper describes the design of the KOALA Birth Cohort Study, the Netherlands. KOALA is (in Dutch) an acronym for Child, Parent and health: Lifestyle and Genetic constitution. The aim of the KOALA study is to identify factors that influence the clinical expression of atopic disease with a main focus on lifestyle.

\section{Lifestyle factors and development of atopy}

Studies performed in different geographic areas have shown that a western lifestyle predisposes to atopic disease (1). We investigate the role of vaccinations, antibiotics, different dietary habits (breastfeeding, organic foods, and vegetarian diet) and alternative child rearing practices (anthroposophy) in early life in the subsequent development of atopy.

Although several studies have suggested that breastfeeding is protective, results of the available studies so far are inconsistent $(6,7)$. Breast milk contains immunologic factors [e.g., cytokines, chemokines, immunoglobulin A (IgA) antibodies] and dietary factors such as fatty acids that can be beneficial for the recipient infant (8-11). We aim to investigate whether immunologic factors and fatty acid patterns in breast milk depend on the mother's atopic constitution. In addition, the role of essential fatty acids and immunologic factors on atopic outcomes in breast-fed children is studied.

The composition of the intestinal microflora in early life is strongly influenced by dietary, environmental, and lifestyle characteristics. Alm et al. (12) showed that lifestyle factors associated with an anthroposophic way of life correlated with differences in infant gut flora. These studies indicate that the composition of gut flora might influence the development and priming of the immune system, which in turn could affect the risk of atopy $(13,14)$. In the KOALA study, we determine gut flora composition in infants at the age of 1 month. Also the relation with the development of atopy later in life will be investigated. To determine this microbial flora, we are currently developing several species and genus specific realtime PCR assays. This culture-independent technique can be used on both fresh and frozen samples and overcomes many of the problems associated with traditional bacteriologic culturing, such as the low sensitivity and reproducibility and the inability to detect non-culturable bacteria.

Another aim in the KOALA study is to address the role of infections and vaccinations in early life in the subsequent development of allergies, the so-called hygiene hypothesis. We look at the role of gastrointestinal infections in relation to development of atopic dermatitis and food allergy in the first year of life and focus on infections that occur at young age and that have been related in some way to the development of atopic diseases (rotavirus, norovirus, Bordetella pertussis and parasites Toxocara and Ascaris). Infection will be assessed through the determination of specific antibodies in capillary 
blood samples collected at $1 \mathrm{yr}$ of age. By combining the sampling dates with data from routine surveillance on seasonal occurrence of the diseases under study, the most probable period of infection will be mapped to 6-month intervals.

Familial pre-disposition has historically been identified as an important risk factor in asthma and atopic diseases (15). However, it is difficult to discriminate between the effect of genes and the effect of environmental factors, because both cluster in families. Therefore, in order to understand the familial aggregation of atopic diseases, genes, and environmental factors should be studied in combination. The KOALA study aims at selecting genes important to the regulation of the innate immune system. Examples of candidate genes are polymorphisms in CD14, toll-like receptors, MYD88, INF- $\gamma$, IL-12, IL-10, IL-4, and IL-13 genes. Buccal swabs from parent-child trios are collected for DNA isolation. Adequate power for gene-environment interaction is assured by combining data from the KOALA study with two other cohorts in the Netherlands.

\section{Design}

The KOALA study is a prospective birth cohort study. Pregnant women have been recruited from an ongoing prospective cohort study $(\mathrm{n}=$ 7020) on pregnancy-related pelvic girdle pain (PPGP study) among pregnant women in the Netherlands (16). Enrolment started in October 2000 and aimed at women at 14-16 wk of gestation. At 34 wk of gestation, PPGP subjects were asked to participate in the KOALA study ('conventional participants'). Additionally, recruitment of pregnant women with alternative lifestyles ('alternative participants') started through several 'alternative' recruitment channels, i.e., posters in organic shops, anthroposophic doctors and midwives, anthroposophic under-five clinics, Steiner schools, and magazines for special interest groups. Like for the PPGP cohort, in this alternative population pregnant women were enrolled at 14-18 wk of gestation. In order to evaluate selective participation of PPGP participants in the KOALA study, we took a short recruitment questionnaire on family history of allergy and asthma and on infant care intentions [use of medication or vaccinations, dietary habits (regular, organic, and vegetarian) and intention to breastfeed] at the time of enrolment.

Perinatal determinants and exposure data on determinants of atopy (hygiene, infections, nutritional data, child rearing, and other lifestyle characteristics) were collected for all members of the cohort by repeated questionnaires during pregnancy and during the first 2 yr of the infant's life at 3, 7, 12, and 24 months post-partum. Follow-up at 3 and 7 months post-partum was completed with high response rates (respectively $90 \%$ and $88 \%$ for conventional participants, and $97 \%$ and $97 \%$ for alternative participants).

Participants recruited from January 2002 onwards (conventional and alternative) were asked to consent to maternal blood sampling $(\mathrm{n}=1355)$ around $36 \mathrm{wk}$ of gestation (for determination of IgE) (subcohort named KOALASUB). KOALA-SUB participants were also asked to consent to sampling infant's feces at 1 month post-partum (for determination of gut flora composition; $\mathrm{n}=1176$ ) and breast milk at 1 month post-partum (for measurement of immunologic markers and fatty acids; $n=317$ ). Furthermore, they were asked to consent to collecting of capillary blood at the age of $1 \mathrm{yr}$ $(n=956)$ and venous blood at the age (collected at the time of writing) of $2 \mathrm{yr}$ for the determination of infection serology and the measurement of total and specific IgE levels. Buccal swabs from trios (the child and both parents) as source of DNA for genetic analysis were collected at the time of writing. All biosamples have been stored frozen in a biobank to which access is granted to the participating research groups following a review of protocols by the KOALA steering committee.

When the child is $2 \mathrm{yr}$, the main atopic outcomes are eczema, total and specific IgE and food allergy. Questionnaires sent to all participants around the child's age of 7, 12, and 24 months include the International Study of Asthma and Allergies in Childhood questionnaire (17).

At $2 \mathrm{yr}$ of age, children participating in KOALA-SUB are visited at home. During these home visits manifestations of atopic dermatitis are observed using the UK working party criteria for atopic dermatitis (18-20) and severity of atopic dermatitis is scored using the severity scoring of atopic dermatitis index (21). Furthermore, total and specific $\operatorname{IgE}$ is assessed at age 1 and $2 \mathrm{yr}$ in KOALA-SUB participants. The home visits at $2 \mathrm{yr}$ of age will be completed in 2005.

All participants had signed informed consent. Ethical approval was obtained from the medical ethics committee of the Maastricht University/ University Hospital of Maastricht. Genetic testing was also included in the medical ethical committee and informed consent procedures. 


\section{Definitions}

In the recruitment questionnaire, the questions on family history of allergy and asthma were phrased as follows: 'Did you ever had allergic complaints such as eczema, hay fever, house dust (mite) allergy and/or food allergy?', and 'Did you ever had asthma or asthmatic bronchitis?', for both parents separately. Both questions could be answered by 'yes', 'no' or 'unknown'. We defined a family history of allergy or asthma as present ('yes') in one or both parents.

Questions on infant care intentions were phrased as: 'Do you adhere to a certain philosophy of life for which you: (i) consciously restrict use of medication (e.g., antibiotics) (yes, no, unknown), (ii) consciously have lower vaccination uptake (yes, no, unknown), (iii) consciously choose an organic, vegetarian or macrobiotic diet (yes, no, unknown) than most other Dutch people?' and 'How do you intent to feed your baby?' (breastfeeding, formulae, both, do not know).

At 7 months post-partum, we asked parents whether they had their child vaccinated by the standard Dutch Vaccination Program Scheme or whether they made use of an alternative scheme, or had this child not vaccinated at all. An 'alternative vaccination scheme' was defined as: delayed vaccination scheme or alternative vaccine composition (e.g., omitting the pertussis component from the diphtheria/pertussis/tetanus/polio vaccine).

We asked parents if their child had ever used antibiotics (yes/no); whether the child had been exposed to environmental tobacco smoke (ETS) for more than $1 \mathrm{~h} / \mathrm{wk}$ (yes/no) and if they had pets in the house at any time (yes/no). Breastfeeding during the first 4 months was categorized as 'exclusive', 'non-exclusive' and 'never'. We defined 'exclusive' as breastfeeding without any artificial feeding and/or supplemental feeding. Consumption of organic bananas (fresh) (yes/no) and organic fruit (jar) (yes/no) were used as indicator variables for choice for organic foods when starting supplemental feeding, because these were the foods most used in the first 7 months.

\section{Results}

In total, 2834 pregnant women were included in the KOALA study, of whom 491 through alternative recruitment channels. The recruitment questionnaire was filled in by 3723 PPGP (candidate population) participants that do not participate and by 2329 of 2343 PPGP participants that actually participate in the KOALA study; the same information was present for all 491 alternative participants. As shown in Table 1, the percentage of parents with allergic history is higher in the participants compared with non-participants: $66.5 \%$ of the newborns recruited from the PPGP study and $73.5 \%$ of alternative participants have at least one parent with allergic history, whereas in the non-participants (PPGP participants not willing to participate in the KOALA study) this is $60.0 \%$. A similar finding was apparent for parental asthma: $29.2 \%$ of the newborns recruited from

Table 1. Characteristics of KOALA non-participants $(n=3723)$ and participants $(n=2343)$ from candidates of pregnancy-related pelvic girdle pain (PPGP) study, and of KOALA alternative participants $(n=491)$

\begin{tabular}{|c|c|c|c|}
\hline & \multicolumn{2}{|c|}{ Candidates from PPGP study } & \multirow{2}{*}{$\begin{array}{l}\text { Alternative recruitment channels } \\
\text { KOALA alternative } \mathrm{n} / \mathrm{N}(\%)\end{array}$} \\
\hline & Non-KOALA n/N (\%) & KOALA conventional $\mathrm{n} / \mathrm{N}(\%)$ & \\
\hline Parental allergy & $2156 / 3723(60.0)$ & $1548 / 2329(66.5)$ & $361 / 491(73.5)$ \\
\hline Parental asthma & $857 / 3723(23.0)$ & $680 / 2329(29.2)$ & $127 / 491(25.9)$ \\
\hline Maternal age (mean, yr) & 31.4 & 31.7 & 33.7 \\
\hline \multicolumn{4}{|l|}{ Maternal education } \\
\hline Primary school & 21/3640 (1.0) & 3/2295 (0.0) & 2/489 (0.0) \\
\hline Preparatory vocational or lower general secondary education & $544 / 3640(15.0)$ & $364 / 2295(15.9)$ & $16 / 489(3.3)$ \\
\hline Vocational education & $1277 / 3640(35.1)$ & $703 / 2295(30.6)$ & $52 / 489(10.6)$ \\
\hline Higher general secondary or pre-university education & $409 / 3640(11.2)$ & $251 / 2295(10.9)$ & $51 / 489(10.4)$ \\
\hline Higher vocational or academic education & $1212 / 3640(33.3)$ & $981 / 2295(42.7)$ & $357 / 489(73.0)$ \\
\hline Other & $177 / 3640(4.9)$ & $93 / 2295(4.0)$ & $11 / 489(2.2)$ \\
\hline \multicolumn{4}{|l|}{ Lifestyle } \\
\hline Smoking during pregnancy & $428 / 3671(11.7)$ & 192/2314 (8.3) & 6/491 (1.2) \\
\hline Different dietary habits & $147 / 3532(4.2)$ & $151 / 2310(6.5)$ & $358 / 488(73.4)$ \\
\hline \multicolumn{4}{|l|}{ Lifestyle intention } \\
\hline Intention to restricted use of medication & $224 / 3543(6.3)$ & $171 / 2317(7.4)$ & $308 / 489(63.0)$ \\
\hline Intention to lower vaccination uptake & $105 / 3541(3.0)$ & 84/2313 (3.6) & $229 / 489(46.7)$ \\
\hline Intention to breastfeed & $2252 / 3540(63.6)$ & $1638 / 2309(70.9)$ & $457 / 489(93.4)$ \\
\hline
\end{tabular}


Table 2. Child characteristics of the conventional $(N=2343)$ and alternative subcohort ( $\mathrm{N}=491)$ in the KOALA Birth Cohort Study over the first 7 months after birth vs. $14.0 \%$ ). Almost half of participants in both subcohorts had at least one pet in the home. Exclusive breastfeeding over the first 4 months was given in a considerably larger proportion of the alternative subcohort $(60.3 \%$ vs. $23.0 \%)$. Of children that had consumed bananas and fruit in jars, these food products had an organic origin in $56.3 \%$ and $64.1 \%$, respectively, of the alternative subcohort, but only $5.4 \%$ and $7.8 \%$, respectively, of the conventional participants.

\section{Discussion}

The KOALA Birth Cohort Study has succeeded in recruiting a large population of participants $(n=2834)$ with various lifestyle choices. Therefore, we have a fairly large contrast in exposure to dietary habits (including breastfeeding, organic foods and vegetarian diet), vaccination schemes and/or antibiotic use in the first $2 \mathrm{yr}$ of life, a period when exposure to these exposures may influence the development of the immune system.

Another strength of this study is the large number of infants of which faecal samples $(\mathrm{n}=$ 1176) have been collected because previous studies on intestinal gut flora and atopy were all based upon much smaller populations (13, 2224). Finally, other unique features of our study are the large number of children with capillary blood samples at age $1 \mathrm{yr}$ and large proportion of participants that have consented with genetic studies.

It is well known that families with allergic complaints tend to be over-represented in studies on the etiology of atopy. The difference between the participants and non-participants may be explained by self-selection, because people with a positive family history of allergic disease will tend to be more interested in participating in a study on health-related topics. Also, the healthconscious lifestyle in the alternative group may be associated with greater willingness to report diseases in general, and consequently with overreporting of allergic complaints. Yet another possible explanation for the higher prevalence of atopic family history in the alternative group is that people choose their alternative lifestyle partly for the reason of their allergic disease. The latter notion stresses the need for stratification on family history in the statistical analysis, to avoid confounding between family history and lifestyle in our study as well as in other cohort studies.

Mid 2006 we expect to report our first results on the relationship between the various exposures in early life and childhood atopy. 


\section{References}

1. Anonymous. Worldwide variation in prevalence of symptoms of asthma, allergic rhinoconjunctivitis, and atopic eczema: ISAAC. The International Study of Asthma and Allergies in Childhood (ISAAC) Steering Committee. Lancet 1998: 351: 1225-32.

2. Bleecker ER, Postma DS, Meyers DA. Genetic susceptibility to asthma in a changing environment. Ciba Found Symp 1997: 206: 90-9.

3. McNally NJ, Phillips DR, Williams HC. The problem of atopic eczema: aetiological clues from the environment and lifestyles. Soc Sci Med 1998: 46: 729-41.

4. Pershagen G. Can immunization affect the development of allergy? Pediatr Allergy Immunol 2000: 11: 26-8.

5. Alm JS, Swartz J, Lilja G, Scheynius A, Pershagen G. Atopy in children of families with an anthroposophic lifestyle. Lancet 1999: 353: 1485-8.

6. Kramer M, KaKuma R. Maternal dietary antigen avoidance during pregnancy and/or lactation for preventing or treating atopic disease in the child. Cochrane Database Syst Rev 2003: 4: CD000133.

7. Wright AL, Holberg CJ, Taussig LM, Martinez F. Material asthma status alters relation of infant feeding to asthma childhood. Adv Exp Med Biol 2000: 478: $131-7$.

8. Hanson LA, Korotkova M, Haversen L, et al. Breast-feeding, a complex support system for the offspring. Pediatr Int 2002: 44: 347-52.

9. Wright $\mathrm{S}$, Bolton C. Breast milk fatty acids in mothers of children with atopic eczema. Br J Nutr 1989: 62: 693-7.

10. van Gool CJ, Thijs C, Henquet CJ, et al. Gammalinolenic acid supplementation for prophylaxis of atopic dermatitis - a randomized controlled trial in infants at high familial risk. Am J Clin Nutr 2003: 77: 943-51.

11. Thiss C, Houwelingen A, Poorterman I, Mordant A, VAN DEN BRANDT P. Essential fatty acids in breast milk of atopic mothers: comparison with non-atopic mothers, and effect of borage oil supplementation. Eur J Clin Nutr 2000: 54: 234-8.

12. Alm JS, Swartz J, BJorksten B, et al. An anthroposophic lifestyle and intestinal microflora in infancy. Pediatr Allergy Immunol 2002: 13: 402-11.

13. Buorksten B, Sepp E, Julge K, Voor T, Mikelsaar M. Allergy development and the intestinal microflora dur- ing the first year of life. J Allergy Clin Immunol 2001: 108: 516-20.

14. BJORKSTEN B. Effects of intestinal microflora and the environment on the development of asthma and allergy. Springer Semin Immunopathol 2004: 25: 257-70.

15. DufFy DL. Genetic epidemiology of asthma. Epidemiol Rev 1997: 19: 129-43.

16. Bastiaanssen JM, de Bie RA, Bastiaenen CH, Heuts A, Kroese ME, Essed GG, van den Brandt PA, Etiology and prognosis of pregnancy-related pelvic girdle pain; design of a longitudinal study. BMC Public Health 2005: 5: 1 .

17. Asher Mi, Keil U, Anderson HR, et al. International Study of Asthma and Allergies in Childhood (ISAAC): rationale and methods. Eur Respir J 1995: 8: 483-91.

18. Williams HC, Burney PG, Pembroke AC, Hay RJ. The UK Working Party's Diagnostic Criteria for Atopic Dermatitis. III. Independent hospital validation. $\mathrm{Br} \mathbf{J}$ Dermatol 1994: 131: 406-16.

19. Williams HC, Burney PG, Strachan D, Hay RJ. The UK Working Party's Diagnostic Criteria for Atopic Dermatitis. II. Observer variation of clinical diagnosis and signs of atopic dermatitis. Br J Dermatol 1994: 131: 397-405.

20. Williams HC, Burney PG, Hay RJ, et al. The UK Working Party's Diagnostic Criteria for Atopic Dermatitis. I. Derivation of a minimum set of discriminators for atopic dermatitis. Br J Dermatol 1994: 131: 383-96.

21. Anonymous. Severity scoring of atopic dermatitis: the SCORAD index. Consensus Report of the European Task Force on Atopic Dermatitis. Dermatology 1993: 186: 23-31.

22. Buorksten B, Naaber P, Sepp E, Mikelsaar M. The intestinal microflora in allergic Estonian and Swedish 2-year-old children. Clin Exp Allergy 1999: 29: 342-6.

23. Kalliomaki M, Kirjavainen P, Eerola E, Kero P, SAlminen S, Isolauri E. Distinct patterns of neonatal gut microflora in infants in whom atopy was and was not developing. J Allergy Clin Immunol 2001: 107: 12934.

24. Kirjavainen PV, Arvola T, Salminen SJ, Isolauri E. Aberrant composition of gut microbiota of allergic infants: a target of bifidobacterial therapy at weaning? Gut 2002: 51: 51-5. 